\title{
EVOLUCIÓN DEL CONCEPTO DE FAMILIA DESDE LA PERSPECTIVA LEGAL. ESTUdio DE CASO: PROCESOS DE VINCULACIÓN EN FAMILIAS RECONSTITUIDAS EN CONTEXTO DE REINTEGRACIÓN COLOMBIANA
}

\author{
Evaristo Javier Miranda Hoyos ${ }^{1}$ \\ Cindy K. Torres A. ${ }^{2}$ \\ J. F. Agredo Morales ${ }^{3}$
}

\section{Resumen}

Esta investigación surgió a partir de los debates que se han generado en relación con el concepto de familia que ha venido desarrollando en una línea jurisprudencial la Corte Constitucional colombiana, al analizar de forma coherente, constructiva y crítica los distintos cambios históricos y legales en cuanto al concepto de familia y desde la antropología cultural, sobre el por qué se han materializado dichos cambios desde el punto de vista jurisprudencial y confrontarlo con un ejercicio investigativo/interventivo con reintegrados y sus familias pertenecientes a la Agencia para la Reincorporación y Normalización (ARN), entidad gubernamental que direcciona los programas y acciones, que desde la Política Pública para la reintegración de los excombatientes a la vida civil, gestiona el gobierno nacional, para comprender y movilizar los procesos de vinculación en y con el sistema conformado, familias, reintegradores e investigadoras/interventoras, en función de su autonomía, que presentaran problemas familiares, analizando los procesos de coevolución en todos los actores del contexto, teniendo presente la influencia de una problemática actual del país que desenvuelve dentro de un marco sociopolítico y legal.

La metodología utilizada fue la investigación/intervención de segundo orden, cuyos participantes fueron dos familias de diferentes regiones del país, una quien mencionaba tener problemas familiares y otra quien fue seleccionada por la profesional de la institución. Se realizaron doce escenarios conversacionales, cuatro con la primera familia, siete

${ }^{1}$ Magister en Derecho Universidad del Norte, Barranquilla. Abogado Especialista en Derecho Civil y de Familia, Universidad del Norte, Barranquilla. Docente Área de Derecho Privado; Corporación Universitaria del Caribe CECAR. Email: evaristo.miranda@cecar.edu.co

2 Magister en psicología clínica y de la Familia. Docente Universitaria Uniminuto. Email: cindy.torres@usantotomas.edu.co

3 Docente Universitaria. Email: jobana.agredo.unad@gmail.com2 ORCID: 0000-00032144-7226. 


\title{
Evaristo J. Miranda. Cindy K. Torres A. J.F. Agredo Morales
}

con la segunda y un escenario de meta-observación. Los resultados dan cuenta de la coconstrucción de nuevas nociones del problema, reconocido desde los conflictos de pareja, la dificultad que representa la ausencia parental y la puntuación del problema desde la significación normativa de los profesionales reintegradores. Se construyeron nuevos significados alrededor de las dinámicas configuradas entre los diferentes participantes y la perspectiva de nuevos futuros posibles a nivel familiar, institucional, social y en el ejercicio de construcción de paz y de la reintegración a la vida civil.

Palabras Clave: Familia, procesos de vinculación, familias reconstituidas, reintegración.

\begin{abstract}
This research arose from the debates that have been generated in relation to the concept of the family that the Colombian Constitutional Court has been developing in a jurisprudential line, by analyzing in a coherent, constructive and critical way the different historical and legal changes as for the concept of the family and from the cultural anthropology, on why these changes have materialized from the jurisprudential point of view and confronting it with an investigative/interventive exercise with reintegrated persons and their families belonging to the Agency for Reincorporation and Normalization (ARN), governmental entity that directs the programs and actions, that from the Public Policy for the reintegration of ex-combatants to the civil life, manages the national government, to understand and mobilize the processes of linkage in and with the conformed system, families, reintegrators and investigators/interventors, in function of their autonomy, that presented familiar problems, analyzing the processes of co-evolution in all the actors of the context, bearing in mind the influence of a current problematic of the country that develops within a sociopolitical and legal framework.

The methodology used was second order research/intervention, whose participants were two families from different regions of the country, one who mentioned having family problems and another who was selected by the professional of the institution. Twelve conversational scenarios were carried out, four with the first family, seven with the second and one meta-observation scenario. The results show the co-construction of new notions of the problem, recognized from the couple's conflicts, the difficulty represented by the parental absence and the score of the problem from the normative significance of the reintegration professionals. New meanings were constructed around the dynamics configured between the different participants and the perspective of possible new futures at the family, institutional, social level and in the exercise of peace building and reintegration into civil life.
\end{abstract}

Keywords: Family, bonding processes, reconstituted families, reintegration. 
Evolución del concepto de familia desde la perspectiva legal. Estudio de caso

\section{Introducción}

ctualmente, es menos frecuente que las familias se conformen exclusivamente por los lazos de consanguinidad, estos cambios están dados por las transformaciones en las estructuras sociales, económicas, políticas y culturales. Las nuevas conformaciones familiares, entre ellas las familias reconstituidas, demandan a su vez la construcción de nuevas formas de organización de las sociedades humanas. El presente trabajo investigativo realiza un análisis histórico, normativo, antropológico y jurisprudencial de la evolución del concepto de familia, teniendo en cuenta la ley 54 de 1990, la Constitución Política de 1991 y los distintos pronunciamientos de la Corte Constitucional hasta el año 2016. A su vez se estudia si la evolución de este concepto ha implicado un avance en la protección de los derechos fundamentales y los distintos cambios que ha tenido la institución de la familia para identificar las distintas formas de conformación y regularización normativa en cuanto a las relaciones jurídicas sociales y familiares.

Para ello analiza los diferentes cambios estructurales y el constante cuestionamiento social frente a la conformación de familias diversas, teniendo en cuenta derechos que se le reconocen a toda persona como titular de derechos y que la misma Constitución Política de Colombia de 1991 defiende. Para definir la familia en el presente artículo conceptualizaremos los diferentes tipos de familia a través de la historia, abordando distintas etapas. Entre ellas la etapa primitiva, la cual para algunos doctrinantes se confunde con la aparición del ser humano. En su fase evolutiva nos apropiaremos del concepto de familia en la etapa medieval y el valor importante que tuvo por la influencia de la doctrina cristiana. En la actualidad, se reconocerá la familia contemporánea en la historia, como institución emergente y variable, es menos frecuente que las familias se conformen exclusivamente por los lazos de consanguinidad, estos cambios están dados por las transformaciones en las estructuras sociales, económicas, políticas y culturales. Las nuevas conformaciones familiares, entre ellas las familias reconstituidas, demandan a su vez la construcción de nuevas formas de organización de las sociedades humanas.

Como parte del proceso de auto-organización de las familias y adaptación a los cambios y demandas evolutivas, se reconoce la posibilidad de 
que se presenten diversos problemas y dilemas, que para el presente estudio, se complejizan en relación con el contexto sociopolítico en el que se encuadra el fenómeno de estudio: la reintegración a la vida civil después de años de participación en el conflicto armado en Colombia.

Este fenómeno representa un reto por la responsabilidad social que implica como profesionales la construcción de conocimiento e intervención con personas y grupos en las circunstancias que actualmente vive el país. Para la construcción de los antecedentes investigativos se realizaron dos estados del arte entre ellos un Estado del arte documental basado principalmente sobre tres ejes temáticos identificados: Familias reconstituidas, proceso de auto organización y conflicto armado y reintegración y un Estado del arte testimonial que recoge las comprensiones realizadas a partir del proceso dialógico dado con familias reconstituidas, con psicólogas clínicas con experiencia en terapia con familias reconstituidas y una profesional del ARN que coordinaba el trabajo llevado a cabo con las familias vinculadas a la institución.

En la convergencia de las voces de autores de la literatura consultada y las voces de personas que participaron compartiendo sus experiencias de ser familia reconstituida, de trabajar con estas familias o de trabajar en el contexto de reintegración, se pueden comprender varios aspectos que enriquecen el proceso de investigación/intervención en relación con los ejes temáticos emergentes que guiaron la construcción del estado del arte documental (ver figura 1).

Figura No. 1: Familias Reconstruida

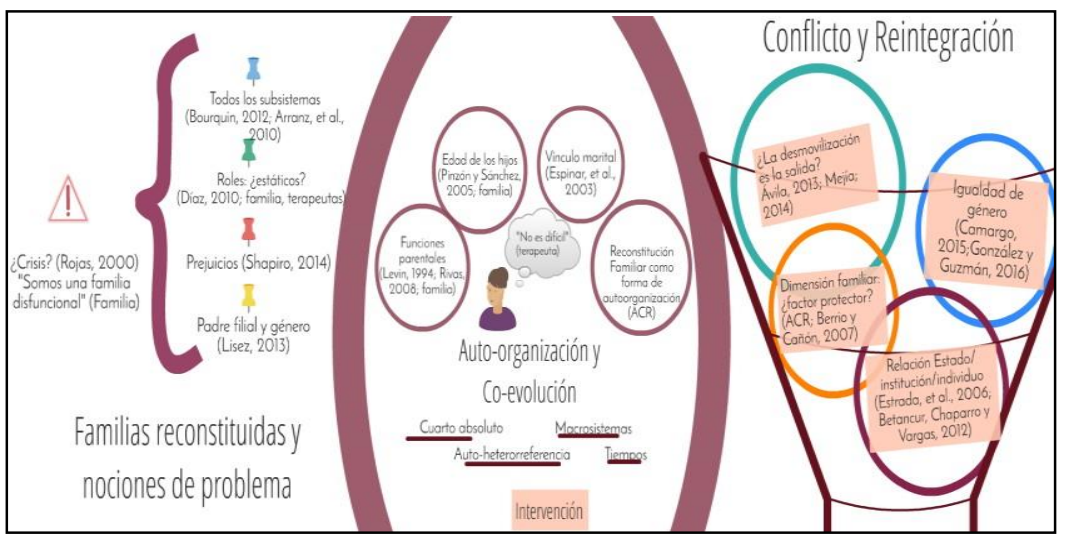


Revisando algunos conceptos de familia encontramos, que esta "se entiende como los miembros de un núcleo familiar que están bajo la potestad del jefe de la familia y que lo determina sea el vínculo de parentesco de consanguinidad y civil" (Talciani, 1990, 17). En el caso de la carta constitucional en el artículo 42 es definido como "el núcleo fundamental de la sociedad el cual se constituye por vínculos naturales o jurídicos, por la decisión libre de un hombre y una mujer de contraer matrimonio o por la voluntad responsable de conformarla" (Constitución Política de Colombia, 1991). En salas de revisión de la Corte Constitucional, como se expresa en la sentencia T - 572 de 2009, familia es "aquella que no sólo se constituye por vínculos jurídicos o de consanguinidad, sino que puede tener un sustrato natural o social, a partir de la constatación de una serie de relaciones de afecto" (Corte Constitucional, 2009).

Adicionalmente, no todas las familias tienen permanencia estable en el tiempo, dando lugar a las familias reconstituidas las cuales: "afrontan dos circunstancias interactivas que les confieren una peculiaridad específica: una reorganización sistémica compleja, más allá de la que se pueda producir en las adoptivas o monoparentales, y el inicio y consolidación de relaciones entre personas con vínculos familiares legales pero no biológicos, entre madrastras, padrastros, hijastros, hijastras y hermanastros" (Arranz, Oliva, Olabarrieta, \& Antolín , 2010, 505).

\section{Concepto de familia en la historia desde la perspectiva legal y el concepto de familia desde la antropología cultural.}

El concepto de familia en la historia se ha caracterizado por una actualiza- ción llevada de la mano de los cambios sociales y culturales. Es decir, no hay un único origen del término familia. Por ejemplo a nivel etimológico es incierto el origen de la palabra. Monroy Cabra (2012), anota que no hay certeza del origen del término. Algunos consideran que la palabra familia proviene de la voz etrusca Famel, que significa esclavo y esta a su vez del antiguo latín famulus, que significa siervo, esclavo (OlivaGómez \& Villa- Guardiola, 2013, 12). 
Con relación al concepto de familia, Conrad Phillip Kottak (2003) explora opciones desde la antropología cultural, siendo esta una ciencia holística y comparativa al contrastar las costumbres de una sociedad con las de otras (Kottak, 2003). El enfoque usado es el de la antropología cultural conformado y conceptualizado el concepto de familia a través de la historia. En ese sentido, es más consecuente con los cambios que se dan en materia de la diversidad humana en el tiempo y el espacio. Esta antropología, estudia la condición humana, su pasado, presente y futuro; su biología, sociedad, el lenguaje y la cultura que en la conformación de la familia...

En cuanto a Levi Strauss (Andrade, 2009), plantea que la Antropología se orienta a un conocimiento global del hombre y abarca el objeto en toda su extensión geográfica e histórica; aspira a un conocimiento aplicable al conjunto de la evolución del hombre, desde los homínidos hasta las razas modernas y tiende a conclusiones, positivas o negativas, pero válidas para todas las sociedades humanas, desde la gran ciudad moderna hasta la más pequeña tribu melanesia (Andrade, 2009, pág. 113)

Según Engels, citando a Morgan (1884), para desarrollar el concepto de familia, es necesario desglosar la clasificación del libro del origen de la familia, la propiedad privada y el Estado, de donde se extraen algunos tipos de familia. Entre ellos mencionaremos varias etapas, a saber: i) la familia consanguínea en donde se explica la clasificación de los grupos conyugales en generaciones de ascendientes y descendientes, donde existía entre ellos un comercio carnal recíproco, donde predominaban la promiscuidad sexual; ii) la familia punalúa, en la cual el comercio sexual disminuye y se excluyen a los hermanos del comercio sexual; iii) la familia sindiásmica, donde se notan vestigios de la poligamia, en este caso poliginia, donde el hombre vive con varias mujeres, pero a la mujer se le exige fidelidad. Finalmente se asume en la monogamia la civilización surge y nace la institución del matrimonio que ha predominado en el Derecho de Familia durante muchas generaciones (Engels, 1884).

Por otro lado, en un estudio interdisciplinar de Irene Lorenzo-Rego (2014) se esboza que para el caso español del Siglo XX, había diversidad de formas de conformación en la familia y estas formas eran predominan- 
tes en la sociedad española. Sin embargo, en el sistema español, las convicciones religiosas fueron limitantes para las que no estaban relacionadas con el modelo legal, Menciona Lorenzo-Rego que "el concepto de familia del Derecho Español plantea las diferentes instituciones del ordenamiento jurídico español que contemplan la familia desde la promulgación de la Constitución española de 1978” (Lorenzo-Rego, 2014).

Sergio Estrada Vélez (2011) de la Universidad de Medellín en su estudio sobre "Algunas Reflexiones en defensa del derecho de las parejas del mismo sexo a constituir Familia y de los menores a tenerla" indica que la unión de parejas del mismo sexo explica cómo los cambios culturales a nivel mundial y nacional, impulsan el reconocimiento de derechos de parejas del mismo sexo, así como el reconocimiento de la adopción. Finalmente, resalta la importancia del matrimonio como de las uniones maritales de hecho para estas parejas. El eje central de su argumentación, es la importancia de los derechos consagrados en la Constitución Política de Colombia, tales como el poder constituir y tener una familia (Estrada-Vélez, 2011).

Rocío Peña-Huertas y María Mónica Hurtado (2014) de la Universidad del Rosario, identificaron la inclusión de los derechos en las democracias y establecen esto como un tema no resuelto. En su investigación tratan de encausar al legislador en la base popular que tiene el parlamento y en las funciones constitucionales que le corresponden; estudian la sentencia C 577 del 26 de julio de 2011, en la que la Corte Constitucional se pronuncia sobre expresiones del contrato de matrimonio y la discusión sobre los derechos de las parejas LGTBI. Con relación a este mismo estudio se establecen valores en los que proponen la inclusión de los derechos de las parejas del mismo sexo y el derecho que tienen a unirse en matrimonio (Corte Constitucional, 2011).

María Cristina Coral y Franklin Torres Cabrera en el libro "Instituciones del derecho de Familia" enuncian "la familia como entidad o grupo, en un valor primario, por ser expresión natural del ser humano, con todas sus esencias: biológica, afectiva, intelectiva, por eso hablan de un grupo natural a la cual se agregan atributos y requisitos de la respectiva cultura" (Coral \& Torres, 2002, 5). 
En el artículo de Investigación "La familia y el artículo 29 de la constitución italiana: algunas reflexiones" de Marco Baldoni, él contempla el reconocimiento de las uniones fundadas sobre vínculos diversos del matrimonio. Baldoni con cierta reserva reconoce la existencia de familias que nacen de relaciones diversas, pero solo si están vinculadas a través de la institución del matrimonio no en las uniones de hecho (Hernández y Ortega, 2013).

\section{Cambios del concepto de familia en la historia.}

Según Augusto Cesar Belluscio, en palabras de Monroy Cabra (2012) el vocablo familia puede ser entendido en tres sentidos, así:

En sentido amplio, según este autor, la familia es el conjunto de personas con los cuales existe algún vínculo jurídico de orden familiar. Comprendería según Fassi "al conjunto de ascendientes, descendientes y colaterales de un linaje", incluyendo los ascendientes descendientes y colaterales del cónyuge, a lo cual habría que añadir al propio cónyuge que nos es pariente; En sentido restringido, la familia comprende solo el núcleo paterno-filial denominado familia conyugal o pequeña familia, es decir la agrupación formada por el padre, la madre y los hijos que viven con ellos o que están bajo su potestad; En sentido intermedio, la familia es el grupo social integrado por las gentes que viven en una casa, bajo autoridad del señor de ella. (pág. 2)

Igualmente, otros autores se han dado a la tarea de estudiar esta temática y aproximar sus ideas a una conceptualización.

En la historia de la sexualidad Foucault (1978) plantea al menos de una manera constante que la sociedad en su futuro y su fortuna están ligados no sólo al número y virtud de sus ciudadanos, no sólo a las reglas de sus matrimonios y a la organización de las familias, sino también a la manera en que cada cual hace uso de su sexo (pág. 18). 
En este mismo contexto, el jurista Enrique Díaz de Guijarro (2016), define la familia como: "la institución social permanente y natural, compuesta por un grupo de personas ligadas por vínculos jurídicos emergentes de la rela- ción intersexual y de filiación” (pág. 194).

\section{Teorías sobre la familia}

Teoría religiosa: Teniendo en cuenta la teología cristiana y en textos extraídos de la Biblia es relevante mencionar que la familia tiene su génesis en la teoría cristiana. Es decir, Dios al crear el mundo a su vez creo a Adán y como ayuda y compañía de éste creó a Eva. Este puede ser considerado como el primer matrimonio del mundo, pues Dios en génesis 1:28 los bendice y les da el propósito de señorear la tierra y de reproducirse. A continuación se hará una mención de las citas bíblicas que se toman como base de esta teoría:

Génesis 1: 26-28 y 2:15, 18, 21,24 “1:26 Entonces dijo Dios: Hagamos al hombre a nuestra imagen, conforme a nuestra semejanza; y señoree en los peces del mar, en las aves de los cielos, en las bestias, en toda la tierra, y en todo animal que se arrastra sobre la tierra.1:27 Y creó Dios al hombre a su imagen, a imagen de Dios lo creó; varón y hembra los creó. 1:28 Y los bendijo Dios, y les dijo: Fructificad y multiplicaos; llenad la tierra, y sojuzgadla, y señoread en los peces del mar, en las aves de los cielos, y en todas las bestias que se mueven sobre la tierra. (Bustos, 2003) 2:15 Tomó, pues, Jehová al hombre, y lo puso en el huerto del Edén, para que lo labrara y lo guardase.2:18 Y dijo Jehová Dios: no es bueno que el hombre esté solo; le haré ayuda idónea para él.2:21 Entonces Jehová Dios hizo caer sueño profundo sobre Adán, y mientras éste dormía, tomo una de sus costillas y cerró la carne en su lugar. 2:24 Por tanto dejará el hombre a su padre y a su madre, y se unirá a su mujer, y serán una sola carne." (Bustos, 2003). 
En Mateo capítulo 19, 1-6, podemos denotar lo siguiente: “19:1 Aconteció que cuando Jesús terminó estas palabras, se alejó de Galilea, y fue a las regiones de Judea al otro lado del Jordán. 19:2 Y le siguieron grandes multitudes, y los sanó allí. 19:3 Entonces vinieron a él los fariseos, tentándole y diciéndole: ¿Es lícito al hombre repudiar a su mujer por cualquier causa? 19:4 El, respondiendo, les dijo: ¿No habéis leído que el que los hizo al principio, varón y hembra los hizo, 19:5 y dijo: Por esto el hombre dejará padre y madre, y se unirá a su mujer, y los dos serán una sola carne? 19:6 Así que no son ya más dos, sino una sola carne; por tanto, lo que Dios juntó, no lo separe el hombre." (Bustos, 2003)

Lo planteado a través de la teoría religiosa fue defendido por Tomas de Aquino en la escolástica planteando que solo lo divino es lo justo, es decir lo que proviene de Dios.

Teoría de la doctrina materialista: en esta teoría, la materialista de la historia de Marx, la producción de los medios inmediatos para la vida, es el factor decisivo en la historia. Engels (1884) al revisar la línea doctrinal de las distintas etapas por las que ha pasado la humanidad, examina el origen de la institución de la familia, revisando fases como el salvajismo, pasando por la época de la barbarie y en últimas aterrizando en la civilización. (Engels, 1884, 1)

Engels en su libro el origen de la familia la propiedad privada y el Estado, hace consideraciones sobre la evolución historia de la familia en el orden mostrado a continuación:

1. La 'primera etapa' la organización social era denominada la 'horda primitiva'. El tipo de familia se tenía como una etapaprefamiliar en la que las relaciones sexuales eran promiscuas debido a que actuaba por instinto y sin limitación de parentesco.

2. La 'segunda etapa' según Engels, es considerada dentro de la organización social denominada 'horda' y que el tipo de familia era la consanguínea. En esta predominaban las relaciones de tipo sexual endogámicas, es decir dentro del propio grupo. En esta 
Evolución del concepto de familia desde la perspectiva legal. Estudio de caso organización se excluyen las relaciones entre los ascendientes y se mantiene entre los hermanos.

3. La 'tercera etapa' la organización social fue denominada 'gens' en el tipo de familia 'púnalua'. En esta las relaciones sexuales son exógenas, es decir fuera del grupo, excluyendo las relaciones sexuales entre hermanos y primos.

4. La 'cuarta etapa' la organización social era la 'fratria' o 'curia' en la que el tipo de familia era denominada 'sindiásmica'. Las relaciones sexuales eran exogámicas, con uniones singulares entre los integrantes, pero poco estable entre las parejas.

5. La 'quinta etapa' es la denominada como 'los pueblos'. En esta el tipo de familia era el patriarcal y las relaciones sexuales eran monogámicas.

Como vemos, este contexto histórico es interesante porque a través de él hay vestigios de cómo los modelos de conformación de familias cambian contantemente, no directamente por el sistema jurídico, sino por las rela- ciones sociales que son considerablemente relevantes para el cambio del concepto de familia. En la historia del concepto de familia existen dos teorías que son fundamento esencial para este concepto y estas son:

Teoría del matriarcado: matriarcado o ginecocracia, es decir el gobierno de las mujeres. Estos conceptos se incluían y entendían dentro del marco propio de la época, cargado de tintes evolucionistas, que se manifestaban en una perspectiva progresista y moralista de la historia. De acuerdo a ella el pasado remoto dominado por las mujeres habría llevado a una situación de "anarquía" (Rodríguez y Serrano, 2005).

Teoría del patriarcado: sustentada en la figura del padre, que corresponde al varón de más edad, como sucedía en el derecho romano (pater), era quien llevaba la dirección familia, sometiéndose los demás miembros a su autoridad y potestad (Monroy, 2012).

En cuanto a la evolución del concepto de familia este estudio muestra que la estructura familiar en la modernidad sufre cambios constantemente 
Evaristo J. Miranda. Cindy K. Torres A. J.F. Agredo Morales

por factores sociales, religiosos, por causa de la emigración constante a las ciudades por parte de campesinos y por la misma industrialización.

\section{Concepto de familia y su evolución en la legislación colombiana}

\section{Familia en el Derecho Civil Colombiano}

En el caso particular de Colombia y su desarrollo normativo, es pertinente mencionar lo relacionado con el Código Civil. En él encontramos que no hay un único aparte donde se integren las normas relativas a la familia. Así, parte de las normas que regulan la familia están contenidas en el libro $1^{\circ}$ 'de las personas' y en el libro $4^{\circ}$, después de las reglas que regulan la prueba de las obligaciones (Monroy, 2012).

Dicho lo anterior, las normas iniciales del Código Civil Colombiano relativas a la familia, han sido modificadas con la expedición de nuevas normas dependiendo de la época y del comportamiento social que fuere necesario regular.

- La Ley 8a de 1922 y la ley 70 de 1931, autoriza la constitución del patrimonio de familia no embargable. A su vez la ley 28 de 1932, regula el régimen patrimonial en el matrimonio.

- La Ley 45 de 1936, regula asuntos sobre la filiación natural. La Ley 83 de 1946, es la Ley Orgánica de la Defensa del Niño. A esta normativa le sucede la Ley 75 de 1968, por la cual se dictan normas sobre filiación y se crea el Instituto Colombiano de Bienestar Familiar.

- El Decreto 1260 de 1970, corresponde al estatuto del registro del estado civil de las personas.

- La Ley 20 de 1974, por la cual se aprueba el concordato entre Colombia y la Santa Sede (Estado del Vaticano) suscrito el 12 de junio de 1973, el cual declarado parcialmente inexequible por la Corte Constitucional.

- El Decreto 2820 de 1976, por el cual se otorgan iguales derechos y obligaciones a las mujeres y a los hombres. La Ley $5^{a}$ de 1975 regula la adopción. 
Evolución del concepto de familia desde la perspectiva legal. Estudio de caso

- $\quad$ Las leyes $1^{\mathrm{a}}$ de 1976 y 25 de 1992, tratan sobre el divorcio, la separación de cuerpos y bienes de matrimonio civil y católico y la cesación de efectos civiles del matrimonio católico.

- $\quad$ La Ley 27 de 1977, por la cual se fija la mayoría de edad a los 18 años. El Decreto 902 de 1988, por el cual se fija la liquidación de herencias y sociedades conyugales vinculadas a ellas ante notario público y se dictan otras disposiciones. El Decreto 2272 de 1989, que organizó la jurisdicción de familia.

- $\quad$ El Decreto 2737 de 1989 conocido como el Código del Menor [i.e. derogado].

- La Ley 54 de 1990, sobre unión marital de hecho modificada por la ley 979 de 2005. La Ley 57 de 1990, sobre matrimonio por poder.

- El Decreto 2651 de 1991 y la Ley 25 de 1992, por la cual se desarrollan los incisos 9, 10, 11, 12 y 13, la Ley 54 de 1990 y Ley 82 de 1993, sobre protección a la mujer cabeza de familia.

- El Decreto 158 de 1994, sobre Afectación a vivienda familiar. Decreto 249 de 1996 sobre normas para prevenir, remediar y sancionar la violencia intrafamiliar (Monroy, 2012).

- La ley 979 de 2005 que modifica parcialmente la ley 54 de 1990 sobre la unión marital de hecho, en la que se establece unos mecanismos agiles para demostrar la existencia de la unión marital de hecho y sus efectos patrimoniales en compañeros permanentes.

Finalmente la ley 1098 de 2006 el cual es un manual jurídico que establece protección de los niños niñas y adolescentes para garantizar desarrollo in- tegral y que crezcan en el seno de la familia y de la comunidad. En las reglas iniciales del Código Civil, estaba regulada las relaciones referentes al concubinatos, pero las posteriores reformas derogaron las disposiciones correspondientes. Esto se puede explicar en parte, para dar una mayor solidez y presencia al matrimonio, incluyendo el católico, como forma pro- totípica, para la época, de confirmar una familia. 


\section{La familia en la Constitución de 1991 y Jurisprudencia de la Corte Constitucional}

La Constitución Política de Colombia, tiene artículos que constitucionali- zan directamente el derecho de familia. Esto corresponde a una tendencia de ubicar directamente en la Carta los valores fundamentales que debe conservar la legislación, con el reto sobreviniente de ajustarse a las varian- tes culturales que se dan en la sociedad. Entre los artículos constitucionales que regulan del derecho de familia tenemos:

- Artículo 5. Considera a la familia como la institución básica de la sociedad.

- Artículo 13. Prohíbe la discriminación en razón del origen familiar, bien sea por vínculo matrimonial, por unión marital o por adopción.

- Artículo 42. La cataloga como el núcleo esencial de la sociedad.

- Artículo 43 expresa que tanto hombre como mujer están en igualdad de condiciones, por lo tanto no existe en nuestro derecho familia matriarcal ni patriarcal porque ambos están en igualdad de condiciones. Además establece que la mujer cabeza de familia es sujeto de especial protección, previendo que esta no sea sujeto de discriminación por su condición sexual ni objeto de violencia.

- Artículo 44. El derecho fundamental del niño a tener una familia y a no ser separado de ella.

- Artículo 45. Protección del adolescente.

- Artículo 46. Obligación del estado, la sociedad y la familia de proteger a los individuos de la tercera edad.

Como lo mencionábamos, la familia moderna y posmoderna en Colombia, hoy tiene un concepto muy distinto en cuanto a su formación. Es decir, 
actualmente la familia no se conforma exclusivamente a través del matrimonio, sino que también surge por vínculos naturales como lo plantea el artículo 42 de la Constitución Política. Esto se fundamenta en el beneficio de todos aquellos que conforman familias por vínculos afectivos, o para favorecerse en situación de vulnerabilidad. En estos casos la Corte Constitucional defiende en sus pronunciamientos estos tipos de familia (Corte Constitucional, 2016).

Entre ellos encontramos 'la familia de tres generaciones' en la que los abuelos ayudan a soportar el funcionamiento doméstico y la economía de las familias, por la incapacidad de poder hacerlo plenamente por los hijos. Encontramos en segunda medida 'la familia acordeón' en donde uno de los padres permanece alejado, por razones de trabajo y estudio y le delega a la madre liderar los procesos familiares pero manteniendo la patria potestad sobre los hijos además de su manutención.

Un tercer tipo es 'la familia de padres divorciados' en la cual la relación marital de los padres termina manteniendo la potestad conjunta de los padres y su manutención.

El cuarto tipo es 'la familia extensa' debido a que este se asemeja a uno de los que se ha presentado a través de la historia como lo es la familia que corresponde al Paterfamilias, en su fase romana de parentesco (Amunátegui-Perelló, 2006). En la familia extensa la relación de parentesco se extiende a más de dos generaciones y está basada en vínculos de sangre en diferentes líneas y grados (abuelos, padres, hijos tíos y primos). Esto permite que en casos donde por ejemplo el niño maltratado o abandonado por sus padres, pueda ser ubicado en este entorno de familia sin recurrir a la adopción como una primera opción.

Un quinto tipo es la 'familia de madre o padre soltero' en la cual individualmente se asume la crianza y manutención de los hijos.

El sexto tipo es la 'familia nuclear', abordada desde el artículo 42 de la Constitución Política de Colombia. Esta comprende solo la relación de esposo, esposa y los hijos biológicos o adoptados, sin excluir la relación entre compañeros permanentes que la Corte Constitucional ha defendido como un vínculo solemne que genera relación de familia reiterado en la Sentencia 075 de 2007. 


\section{La Familia conformada por parejas del mismo sexo}

A partir de los pronunciamientos de la Corte Constitucional de Colombia en revisión de asuntos del derecho de familia, que se han suscitado por la situación fáctica de que es posible que se conformen parejas del mismo sexo, y que estas reclamen efectos jurídicos atinentes al derecho de familia, es importante revisar algunos pronunciamientos que han tenido incidencia en la modificación del concepto de familia y han permitido que en la so- ciedad colombiana se fortalezca la institución que la misma Constitución denomino 'núcleo fundamental de la sociedad'. Por lo anterior, seguida- mente se revisan cronológicamente ordenados, dichos pronunciamientos relevantes para la evolución del concepto de familia.

Sentencia C-098 de 1996: en esta se demanda la constitucionalidad de normas que no toman en consideración las parejas de mujeres o de hombres que cohabitan de manera estable y permanente, generando por este motivo una discriminación. Se consideran vulnerados los preceptos de los artículos 1, 13, 16, 18, y 21 de la Constitución Política. El eje central es el artículo 13, relativo a la igualdad. Según lo expuesto, podemos destacar que la ley 54 de 1990 consagra el régimen patrimonial permanente pero exclusivamente entre la uniones heterosexuales. Las parejas homosexuales pueden encontrarse en idénticas circunstancias, pero no obstante a ella no se les extiende estas disposiciones legales y por consiguiente viola el principio de igualdad real y efectiva.

En esa misma línea, la normativa demandada coarta el desarrollo de la personalidad, artículo 16 de la Constitución Política, puesto que la ley niega la protección a la comunidad de vida entre personas del mismo sexo y su libre desarrollo a la personalidad, pues se niega legalmente admitir que cada persona pueda escoger su orientación sexual.

Finalmente la negativa al amparo patrimonial de los homosexuales desconoce el principio de pluralismo, consagrado en el artículo $1^{\circ}$ de la Constitución, y por otro lado la ley quebranta la honra de las personas homosexuales ya que su unión no es reconocida en nuestro ordenamiento jurídico. La Corte en la decisión consideró:

Primero.- estarse a lo resuelto en la Sentencia C-239 de 1994 en relación con la expresión "a partir de la vigencia de la presente ley" del artículo 
primero; y declarar exequible la parte restante del mismo artículo, que dice: "para todos los efectos civiles, se denomina unión marital de hecho, la formada entre un hombre y una mujer, que sin estar casados, hacen una comunidad de vida permanente y singular. Igualmente, y para todos los efectos civiles, se denominan compañero y compañera permanente, al hombre y la mujer que forman parte de la unión marital de hecho".

Segundo.- declarar exequible, el literal a) del artículo segundo de la Ley 54 de 1990 (Corte Constitucional, 1996).

Como podemos ver en Colombia, gracias a la labor de la Corte Constitucional, hemos pasado de una desprotección total contra las parejas del mismo sexo a conferirle a éstas grandes avances en materia civil, patrimonial, seguridad social, penal, disciplinaria, en los regímenes especiales de pensión, salud, entre otros, lo cual nos muestra que nuestra legislación, no solo reconoce el derecho de la persona particularmente de cual sea su condición sexual, sino que se ha dado la inclusión materializada respecto de esto.

La Corte ha sostenido que la unión marital de hecho, entre parejas heterosexuales, encaja en el concepto de familia constituida por la voluntad responsable de conformarla. Entonces, si se ha hecho extensiva la protección que se les confiere a las parejas homosexuales, y por tal llegar reconocer una nueva forma de familia en nuestra legislación: la homosexual, que teniendo en cuenta la normatividad vigente fue a lo que llegamos.

Sin embargo, es importante recalcar que la Corte Constitucional, pese a todos esos grandes avances, no había aceptado la inclusión de las parejas conformadas por personas del mismo sexo dentro del concepto de familia, que trae la Constitución Política en su artículo 42: "La familia es el núcleo fundamental de la sociedad. Se constituye por vínculos naturales o jurídicos, por la decisión libre de un hombre y una mujer de contraer matrimonio o por la voluntad responsable de conformarla" (Constitución Política de Colombia, 1991). Claramente este concepto iba contrario a lo que se quería llegar, por lo cual se establecieron ciertos alegatos que llevaron a una final conclusión que incluye a los homosexuales en el ámbito de conformación de una familia. 
Respecto a esta Sentencia podemos destacar que desde un primer momento se debió poner en claro el fundamento de llevaba al accionante interponerla dado que en el desarrollo de esta se llevó a colación ciertos temas que de una u otra forma estaban ligados con la sentencia pero no eran tema de discusión al momento de tomar una decisión, puesto que según lo expuesto por la Sala Plena, no se trata de convertir a los homosexuales en "objeto de escarnio público2, como lo dice la Sentencia, sino simplemente de reconocer esta opción en el plano constitucional.

Sentencia C-075 de 2007: sentencia hito, fundadora de línea. En esta la Corte cita constantemente en fallos antecedentes que proveen la argumentación y el análisis del tema que se estudia, en el cual los accionantes aluden que la Ley 54 de 1990, tiene algo poco usual como lo es que el legislador al momento de crearla se convirtió en el único referente normativo del cual se entiende la pareja jurídicamente reconocida dentro del ordenamiento. Es decir la ley definió la figura de compañeros permanentes como aquella formada por dos personas heterosexuales sin incluir la posibilidad de las parejas del mismo sexo. Por esta razón los accionantes consideran que las parejas homosexuales no tienen el mismo acceso al reconocimiento y protección derechos que tienen las parejas heterosexuales.

Idóneos ejemplos de lo anterior sería por ejemplo, la regulación de la violencia intrafamiliar entra a proteger a quien vive con el agresor y esta no tiene aplicación en casos de homosexuales agredidos por su pareja. Por otro lado ninguna persona está obligada a denunciar o el imputado a incriminar a su compañero o compañera permanente, pero los homosexuales si se ven en la obligación de realizar esto, en lo referente al principio de no autoincriminación. En cuanto a la obligación alimentaria a favor de los compañeros permanentes, los homosexuales no gozan de esta protección. En el régimen de afectación a vivienda familiar, la norma establece la figura para los cónyuges o compañeros permanentes que su convivencia sea superior a los dos años y no aplica para los homosexuales. De igual forma los homosexuales no tienen la posibilidad de afiliar a su pareja a los regímenes de salud y pensión o ser beneficiarios de la pensión de sobreviviente, cosa que si pueden acceder las personas del mismo sexo. 
Asimismo constituye una vulneración del principio de la dignidad humana, toda vez que se limita la posibilidad de que los homosexuales tengan un plan de vida y se desarrollen libremente, la libre asociación constituida por la posibilidad de convivir en pareja viviendo libremente su sexualidad, pues esto subsiste por aparte del ideal de familia por lo que se pueden formar de manera diferente.

La Corte tomo la decisión en materia de constitucionalidad de declarar la exequibilidad de la Ley 54 de 1990, modificada por la Ley 979 de 2005, entendiendo también que el régimen de protección contenido en la ley se estará aplicando también a las parejas homosexuales, por cuanto estas de igual forma se encuentran sujetas a la misma protección por parte del Estado y merecen el mismo trato que las parejas heterosexuales, por lo que esta norma en el ámbito de aplicación está comprendida también por las parejas del mismo sexo que conformen una familia.

De tal forma las parejas homosexuales que cumplan con las condiciones previstas en la ley para las uniones maritales de hecho como la comunidad de vida permanente y singular mantenida por un periodo no menos de dos años podrán acceder al régimen de protección dispuesto en la ley, quedan amparadas por la presunción de sociedad patrimonial y sus integrantes podrán acudir a establecerla cuando así lo consideren necesario, esto teniendo en cuenta los medios previstos en la ley.

La realidad de las parejas homosexuales y de las personas que las integran no es reconocida y resulta invisible para el ordenamiento jurídico, puesto que, no obstante que dichas personas han obrado en ejercicio de una opción protegida por la Constitución, son ignoradas por el ordenamiento jurídico cuando se trata de resolver los conflictos patrimoniales que pueden surgir de tal decisión. En ese entendido el régimen de la Ley 54 de 1990, tal como fue modificado por la Ley 979de 2005, en la medida en que se aplica exclusivamente a las parejas heterosexuales y excluye de su ámbito a las parejas homosexuales, resulta discriminatorio.

Se esbozan finalmente diferencias objetivas que existen entre los dos tipos de pareja, y las específicas consideraciones que llevaron al legislador del año 1990 al establecer este régimen de protección, fundadas en la necesidad de proteger a la mujer y a la familia. No es menos cierto que hoy 
por hoy puede advertirse que las parejas homosexuales presentan requerimientos análogos de protección y que no existen razones objetivas que justifiquen un tratamiento diferenciado. Lo anterior en el rango de la decisión de la Corte y los criterios expuestos, no deben llevar a desconocer el ámbito de configuración del legislador para la adopción, en proceso democrático y participativo, de las modalidades de protección que resulten más adecuadas para los requerimientos de los distintos grupos sociales.

Sentencia C-811 de 2007: la Corte decide ampliar el rango de protección de derechos reconociendo cobertura en el régimen de seguridad social en salud del régimen contributivo a las parejas del mismo sexo, como también permite la cobertura previa declaración ante notario, en la cual se demuestre que conviven efectivamente y que mantienen una relación permanente y singular.

Sentencia C-336 de 2008: en este fallo la Corte extiende la protección brindada a las parejas heterosexuales, en igual forma a las parejas del mismo sexo, debido a que no existe fundamento razonable ni lógico para que exista un trato desigual en el ejercicio de sus derechos, al libre desarrollo de la personalidad y a la libertad de opción sexual sin importar que esta decisión esté ligada a una persona de su miso género. Las parejas del mismo sexo deberán asistir ante notario para expresar la voluntad de conformar una pareja singular y de manera permanente, de la cual se coligen efectos jurídicos de prestaciones sociales como lo es la pensión de sobrevivientes.

Sentencia C-798 de 2008: la Corte Constitucional es muy clara al indicar que la obligación alimentaria hace parte del régimen patrimonial de las uniones de hecho de las parejas homosexuales, y que no proteger este derecho en beneficio de el régimen patrimonial de las parejas homosexuales, no es justificable debido a que este derecho fundamental se encuentra amparado a partir del artículo 13 de la Carta Política.

Sentencia T-051 de 2010; esta sentencia la Corte Constitucionalreconoce que las parejas del mismo sexo puedan acceder al reconocimiento y pago de la pensión de sobrevivientes en iguales condiciones que las parejas heterosexuales y en su integralidad. 
Sentencia C-029 de 2009: esta sentencia consolida la línea y es considerada como la sentencia macro, porque reconoce una considerable cantidad de derechos fundamentales inherentes a las parejas del mismo sexo y están conformadas en virtud de la unión marital de hecho. Entre los derechos que reconoce están la igualdad entre las parejas homosexuales como las heterosexuales, la no discriminación a las parejas homosexuales, también manifiesta la Corte que tiene vocación de permanencia e implica asistencia recíproca y solidaridad, reconoce protección constitucional, el amparo de los derechos y beneficios de la ley de justicia y paz en materia de víctimas e indemnización de delitos de desaparición forzada y genocidio, administración de bienes en parejas del mismo sexo, derecho a no incriminar a un compañero permanente ni a declarar en su contra, patrimonio de familia inembargable y el subsidio a vivienda familia. Es importante la sentencia mencionada ya que en esta sentencia la Corte es bastante específica y protege de manera eficaz derechos y garantías en las parejas del mismo sexo y para el concepto de familia establece un marco de derechos para su debida conformación y mecanismos de defensa ante cualquier tipo de vulneración.

Sentencia C - 577 de 2011: en esta sentencia la Corte Constitucional plantea que la protección de los derechos de las parejas del mismo sexo no debe limitarse sólo a aspectos de tipo patrimonial debido a que en las uniones de parejas del mismo sexo existe un componente afectivo y emocional que alienta su convivencia y que puede estar representada a través de manifestaciones de afecto, socorro y ayuda mutua, componente que se encuentra inmerso en las uniones de parejas heterosexuales, en que la Corte aclara que las parejas del mismo sexo también conforman familia y también les asisten deberes de ayuda y socorro mutuo.

En la misma sentencia la Corte plantea que una de las formas de conformación de la familia es el matrimonio y que si bien este vínculo aparece ligado exclusivamente a las uniones heterosexuales, la Corte plantea la posibilidad que el legislador regule la manera de formalizar y solemnizar el vínculo matrimonial entre las parejas del mismo sexo. Aclara la Corte que se reservaría la libertad de asignarle el calificativo y nombre de dicho vinculo. 
Es decir, la interpretación de la Corte al artículo 42 de la Constitución Política, permite la posibilidad que las uniones homosexuales se constituyan con una forma solemne innominada, distinta del contrato de matrimonio, la Corte en Sentencia C-577 de 2011, declaró exequible el texto del artículo 113 del Código Civil Colombiano, por lo cual el matrimonio es un contrato solemne entre hombre y mujer, y sigue reservando este calificativo a las uniones heterosexuales

La Corte destaca el hecho de que en el ordenamiento jurídico colombiano no exista regulación en cuanto a las uniones matrimoniales de las parejas del mismo sexo y constata que existe un déficit en cuanto a la igualdad de derechos fundamentales para las parejas homosexuales. Conforme a tal situación actual armonizando con el principio democrático y el mandato que el Constituyente primario le otorga al Congreso, esta situación debe ser resuelta por el legislador dentro del ámbito de su competencia y además, debe ser en el sentido que adopten medidas que garanticen el goce efectivo de los derechos de las parejas del mismo sexo.

Sentencia SU-214 de 2016: en esta el Magistrado Alberto Rojas Ríos presenta ponencia favorable al matrimonio de las parejas homosexuales. La decisión aprueba dicha postura, y ordena a los jueces y notarios que no podrán negarse a realizar estas uniones. En una histórica votación de seis votos contra tres la Sala Plena de la Corte después de un intenso debate de posiciones favorables y desfavorables todas respetables y en derecho, primó el argumento de la protección de derechos fundamentales, la igualdad, la libertad y la dignidad humana.

El Magistrado Alberto Rojas dejó en claro en su ponencia que el matrimonio no se puede considerar exclusivamente como la unión de un hombre y de una mujer, y que además es una figura que debería ser aplicable sin importar el género. También manifiesta que el matrimonio entre parejas del mismo sexo debe tener los mismos efectos vinculantes que el heterosexual.

En su interpretación sostiene que puesto que los hombres y las mujeres forman parte de la especie humana, para argumentar y defendiendo el derecho a la igualdad de la Constitución Política, en los términos del artículo 
13, y manifestando que a todo colombiano le asiste el derecho a contraer matrimonio sin distinción alguna de raza, sexo, religión, estirpe.

Tomando estos argumentos, se concluyó que la Carta Política es clara al definir el papel trascendental de la familia en el conglomerado social y que en la interpretación constitucional del artículo 42, sea por vínculos jurídicos o naturales, el matrimonio o unión marital de hecho debe tenerse en cuenta la voluntad responsable de la conformación de la familia. Es decir, no debe ser restringida el derecho que le asisten a las personas para la conformación de familias, además sería importante el reconocimiento por parte del Congreso teniendo en cuenta la figura del 'bloque de constitucionalidad' contenida en el artículo 93 de la Constitución Política, el cual señala la prevalencia en el orden interno de los tratados internacionales ratificados por el Congreso que reconocen derechos humanos. El derecho a contraer matrimonio y la protección de la institución de la familia son derechos intangibles inclusive en los estados de excepción.

Para cerrar este aparte de revisión jurisprudencial, se puede decir que se constata de forma que a pesar de todo el tiempo trascurrido, estamos casi que siendo esclavizados de cierto modo, por un sin número de costumbres conservadoras, que no aceptan el libre desarrollo de la personalidad, negándole a la persona por su orientación sexual una serie de derechos y libertades, o un grupo de ellos al ser señalados y rechazados por la sociedad. Es decir, la configuración normativa desnaturaliza sin argumentos válidos para establecer discriminaciones jurídicas de ese tipo al serhumano, creando un ser humano a su antojo y semejanza y conforme a las necesidades sociales y no a la defensa de sus derechos fundamentales. Una consideración sobre la igualdad plena no es tan nueva como se piensa, se puede mencionar el postulado de Aristóteles en donde manifiesta lo siguiente: "El único Estado estable es aquel en que todos los ciudadanos son iguales ante la ley" (Damm, 2008).

\section{Reconstitución familiar}

Para empezar, se significa el proceso de reconstitución familiar como un modo de vida relativamente nuevo que nace a partir de las transformacio- nes sociales, económicas, políticas y culturales a través de la historia, por 
tanto se encuentra un aumento de separaciones de parejas que conformaban familias nucleares o tradicionales. La reconstitución familiar suele asociarse a presencia de crisis en los miembros de la familia como parte de la ruptura organizacional que se experimenta, e incluso por las voces de las mismas familias, se connota como un tipo de familia disfuncional, por la significación de la familia nuclear como el modelo ideal de organización familiar, teniendo en cuenta las culturas, tradiciones e ideas judeocristianas que siguen dominando en algunos grupos y sociedades, entre ellas las latinoamericanas. Aun así, los estudios dan cuenta que no siempre la reconstitución familiar configura un proceso de crisis y que, en muchas familias, la decisión de reconstituir familia representa la posibilidad de construir un mejor devenir para todos. De esta manera, cuando la unión anterior es conflictiva y todos los miembros de la familia se ven involucrados, las expectativas de la nueva pareja del padre o madre, son positivas, facilitando el proceso de adaptación y por tanto, de auto organización, siendo procesos aliados.

Por otro lado, si bien tradicionalmente hablar de crisis es alarmante, también se logra reconocer la crisis como una vía para visibilizar nuevos futuros posibles. La crisis puede configurarse en cualquier de los subsistemas de la familia, desde los hijos hasta los mismos abuelos: Los hijos se enfrentan no sólo a la separación de sus padres, sino a la llegada de un nuevo miembro a la familia, que puede ser permeada por conflicto de lealtades con sus padres. Éstos se deben adaptar también a sus nuevos "hermanos", e incluso, a tener dos hogares, el de la semana y el del fin de semana, suscitando un esfuerzo significativo para asumir dichas situaciones.

Esta configuración familiar emerge en diversas condiciones sociales, culturales, históricas y subjetivas. En el marco de la reintegración parece también ser un elemento importante en las construcciones de familia que realizan las personas que se desmovilizan de grupos armados y empiezan una nueva vida en la legalidad. La reintegración entonces, es un proceso liderado por la ARN, pero que se teje y se construye en las vicisitudes de volver a ser civil después de haber sido guerrillero, e incluso la influencia de la guerra en este mismo proceso. La familia se convierte en uno de los ejes fundamentales en el proceso de adaptación a este nuevo escenario, en 
su proceso de auto organización, lo que lleva a la ARN a establecer el ámbito familiar como una dimensión de su ruta, según el relato de la profesional de la institución, reconociendo también en sus políticas la presencia de familias reconstituidas, incluso cobijando con sus beneficios a los hijos filiales de los participantes bajo una única condición: la cohabitación.

Por lo tanto, el proceso de reintegración tiene presente que un vínculo fuerte en relación a la familia permite una mayor posibilidad de autonomía ciudadana, convirtiéndose a su vez en un factor protector que puede contribuir con la permanencia en la legalidad, por estas razones, la institución hace extensivo los alcances del programa a las familias en pro de su desarrollo y fortalecimiento.

Sin embargo, estas familias no solo comparten los beneficios de la reintegración, también asumen los retos inherentes a este proceso que sumados a las particularidades propias de ser una familia reconstituida pueden generar momentos de crisis, como lo es la a las demandas de una nueva ciudad, y en general de la vida urbana, la independencia económica y el cumplimento de los estadios del proceso de desvinculación y reintegración.

Con respecto a la influencia familiar en la reintegración, se plantea la pregunta de si realmente se puede considerar la conformación de familia como un factor protector o de riesgo, lo que le genera gran interés a la ARN y a los investigadores que se acercan a este fenómeno (Berrio y Cañón, 2007).

El eje de auto organización y co-evolución actúa como puente entre estos dos procesos: el de reconstitución familiar y el de reintegración. Como ya se mencionó, el proceso de auto organización, enfocado en el sistema familiar, no es un proceso necesariamente difícil ni tampoco se deriva directamente de la crisis en todos los casos, sin embargo, se connota la intervención, desde el ejercicio de la Psicología Clínica, como facilitadora de dichos procesos, lo que la misma ARN decanta al reconocer la poca posibilidad de intervención familiar y la demanda de ayuda tan marcada en las dinámicas que se tejen con sus participantes y sus familias. Esto inmediatamente convoca el concepto de co-evolución, como aquel proceso en el que el sujeto, en interacción con su entorno, evoluciona, al 
mismo tiempo que el mismo entorno cambia y se adapta a sus nuevos individuos en transformación.

Es así como, el escenario terapéutico se convierte en un escenario coevolutivo, en un "cuarto absoluto" como lo mencionan Gutiérrez, Caicedo y Fitata (2009) en el que se crean nuevos sentidos y significados a través de la interacción auto-heterorreferencial de los participantes (Garzón y Riveros, 2012) y que desde una perspectiva ecológica e incluso compleja, reconoce que no sólo individuos, sino los tiempos de cada uno de ellos y los mismos sistemas y microsistemas, se dan a la tarea de co-construir nuevas perspectivas en la interacción y el tejido dado a través del intercambio emerge

De esta manera, se puede reconocer entonces la pertinencia de tener en cuenta en la investigación/intervención aspectos relacionados al trabajo con familias reconstituidas (la relación con los sistemas de significación, la satisfacción conyugal, la relación parental, el comportamiento de los hijos, la perspectiva estructural, las estrategias de resolución de conflictos y la identidad familiar, entre otros) mientras emprenden un diálogo con los elementos de la ruta de integración, principalmente los de la dimensión familiar, que reconocen el momento de conformación familiar como una estrategia más para la significación positiva de ser civil por parte de los participantes y la prevención de la reincidencia delictiva, tratando de responder al mismo tiempo si la desmovilización en realidad es la salida (Ávila, 2013; Mejía; 2014).

El proceso investigativo/interventivo necesitó un sustento adicional que soportara la comprensión del fenómeno social que vive la reintegración a la vida civil en Colombia por lo tanto se construyó un marco sociopolítico en donde se tuvieron en cuenta factores como la situación política, social y cultural del proceso en otros países y dar cuenta de cómo emerge entonces la necesidad intervención y acompañamiento de diversas disciplinas a esta realidad que se teje en la actualidad desde este contexto del conflicto. (ver figura 2). 
Figura No. 2: Dimensión de la familia

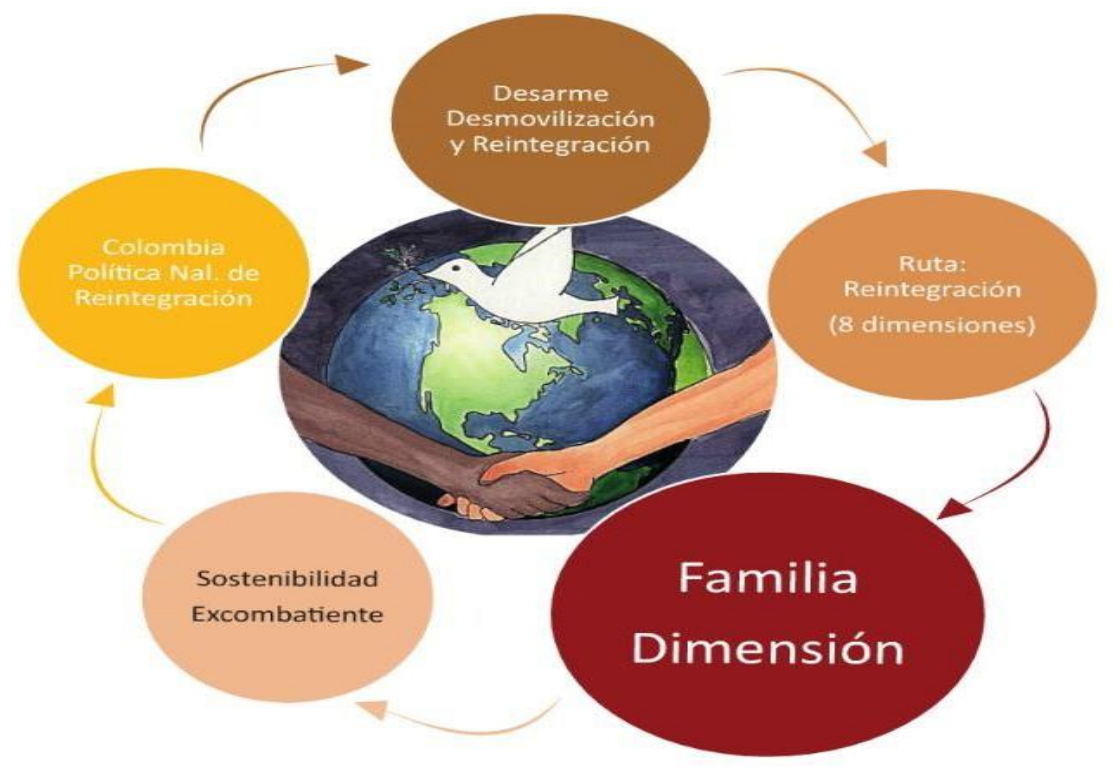

Fuente propia.

La Política Nacional de Reintegración Social y Económica (PRSE) en Co- lombia busca sostener en el tiempo la incorporación del desmovilizado y su familia a las redes de participación del estado, dejando atrás esta condi- ción a través del acompañamiento continuo que garantice la calidad de vida de estas personas. Para conseguirlo tiene como estrategia la corres- ponsabilidad, que pretende, en primera instancia, apoyar al desmovilizado a reintegrarse como ciudadano, y posteriormente, comprometerlo junto con su sistema familiar a la permanencia en la legalidad (Consejo Nacional de Política Económica y Social, CONPES, 2008).

Es importante tener en cuenta que pese a estas políticas, el excombatiente debe enfrentarse a un reto particular en Colombia. Algunas variables que pueden ser vistas como adversas se vuelven inherentes al proceso de reintegración, como por ejemplo, la carencia de ofertas de empleo, la cultura del inmediatismo económico, las diferencias sociales, la inseguridad 
propia de las calles y las invitaciones a retomar su ilegalidad por parte de los grupos al margen de la ley.

La Política Nacional de Reintegración Social y Económica - PRSE en Colombia busca sostener en el tiempo la incorporación del desmovilizado y su familia a las redes de participación del estado, dejando atrás esta condición a través del acompañamiento continúo que garantice la calidad de vida de estas personas. Para conseguirlo tiene como estrategia la corresponsabilidad, que pretende, en primera instancia, apoyar al desmovilizado a reintegrarse como ciudadano, y posteriormente, comprometerlo junto con su sistema familiar a la permanencia en la legalidad (Consejo Nacional de Política Económica y Social, CONPES, 2008).

Es importante tener en cuenta que pese a estas políticas, el excombatiente debe enfrentarse a un reto particular en Colombia. Algunas variables que pueden ser vistas como adversas se vuelven inherentes al proceso de reintegración, como por ejemplo, la carencia de ofertas de empleo, la cultura del inmediatismo económico, las diferencias sociales, la inseguridad propia de las calles y las invitaciones a retomar su ilegalidad por parte de los grupos al margen de la ley.

\section{Metodología}

El presente trabajo se realizó bajo la metodología de investigación/inter- vención, entendiendo que la investigación no puede desligarse de la inter- vención, puesto que como señala Pakman (1999), el proceso de investigar no constituye solamente la recolección de información acumulada previa- mente, sino que se construye por medio de la interacción entre investiga- dor y participante. Es decir que, como lo señala el construccionismo social, los datos recogidos se configuran a partir de la intervención misma del investigador en el momento de investigar, dado que la investigación, es acción. Esta es una investigación/intervención cualitativa de segundo or- den, obedeciendo en primer lugar, al papel del proceso conversacional que configuran intercambios lingüísticos y comunicativos, que en la naturaleza interaccional y reflexiva de los sistemas humanos, se reconocen como principio generador de formas de vida y construcción de lo social (Estupiñán, et al., 2006b). 
En segundo lugar, desde la lógica paradigmática y epistemológica expuesta, las investigadoras- interventoras, se incluyen como participantes en el fenómeno observado, que como ya se mencionó, no es solamente una apuesta metodológica como la de observación participante, que incursionó en el campo de la etnografía, sino como precepto epistemológico que dilucida que no es posible investigar sin involucrarse con el fenómeno, aun cuando la intención sea esta, puesto que los sentidos y significados del investigador empiezan a emerger en el momento mismo en que se construye el fenómeno de estudio. En este sentido, los procesos autorreferenciales son una herramienta metodológica que posibilita la reflexividad de los actores, siendo uno de los elementos de mayor atención y mayor potencia en los modos de operar con los participantes.

Finalmente, vale mencionar que el presente estudio se realizó bajo el modelo de consultoría sistémica, que como mencionan Estupiñán, et al. (2006b), pretende asesorar a familias y organizaciones en la búsqueda de estrategias alternativas para resolver los dilemas y problemas en órdenes psicosociales. Este trabajo es un proceso de reflexión sobre la acción en el contexto de las organizaciones con los equipos de trabajo y los usuarios, por lo que no se llevan a cabo procesos administrativos diferentes a los que se establecen a institucionalmente.

Adicionalmente, la dinámica creada en el contexto de investigación/intervención fue guiada por la lógica abductiva que reconoce tanto el marco epistemológico como los marcos de referencia personales, permitiendo conversar con todo tipo de conocimiento e intuición, con los roles diferentes roles de las investigadoras/interventoras, con los estilos, posturas e identidades. Cuando se habla de abducción, se hace referencia a "un tipo de pensamiento conjetural que consiste en la adopción provisional de una explicación, con el objeto de someterla a verificaciones ulteriores; dicha explicación es formulada provisionalmente por el investigador gracias a la adopción de una ley o norma que obtiene a partir de su conocimiento del mundo y su experiencia previa" (Calvo y Capozzi, 1999, p. 111). 


\section{Diseños metodológicos para los grupos territoriales}

Para la recolección de datos investigativos/interventivos se plantearon es- cenarios conversacionales en los que participaron las familias, las reinte- gradoras asignadas y las investigadoras/interventoras, los mismos se crea- ron en función de la comprensión de los procesos vinculares y la noción del problema, teniendo en cuenta que la figura de la ARN mediaba en alguna medida en las formas de representar tanto los primeros como el segundo. Para su realización se planteaban preguntas orientadoras que servían como focos para generar procesos dialógicos que sirvieran como agentes generadores de comprensiones y reflexiones sobre el fenómeno en estudio.

\section{Contexto y Actores participantes}

Los escenarios conversacionales que fueron co-construidos con los parti- cipantes se llevaron a cabo en dos regiones o grupos territoriales de la ARN: Soacha, Cundinamarca e Ibagué, Tolima. Se trabajó con dos familias reconstituidas, una por cada grupo territorial (GT), tres profesionales de reintegración, una profesional del primer GT y dos profesionales del se- gundo, las dos investigadoras/interventoras y las dos docentes asesoras. El criterio de selección de dichas familias fue principalmente la puntuación de la experiencia problemática a nivel familiar.

- La primera familia fue una familia constituida por los dos cónyuges, siendo la mujer la participante del proceso de reintegración, las dos hijas de la mujer de diferentes uniones y el hijo de la pareja actual, con quienes se realizaron cuatro encuentros en su residencia, dos en compañía de la reintegradora y dos con la presencia física de las dos investigadoras, otras dos por vía telefónica con la investigadora/interventora que reside en Ibagué. La participante se desmovilizó 8 años atrás del grupo armado al margen de la ley FARC, en el año 2008 e inició su proceso de reintegración en este mismo año, 4 meses después de su desmovilización. Vive en la ciudad de Bogotá desde entonces.

- La segunda familia se constituye de la cónyuge, la hija de su primera unión, el cónyuge, quien en este caso es el participante del proceso 
de reintegración, el hijo de la actual unión y una hija menor que se referencia también como hija de los dos cónyuges por acuerdo parental, pero que en realidad es hija de una relación que configuró la cónyuge en un periodo de separación con el participante, la que posteriormente continuó como una relación extramatrimonial. El participante se desmovilizó 6 años atrás, en el año 2010, y se vinculó a la ARN 2 años atrás, en el 2014 por iniciativa propia al recibir información acerca del proceso de reintegración y del auxilio económico que se proveía.

Los reintegradores que hicieron parte del proceso fueron dos profesionales reintegradores que cumplen la función de acompañamiento y un reintegrador clínico que trabajaba con la segunda familia por la demanda clínica que representaba su situación.

\section{Resultados}

Los resultados se analizaron a la luz de los conceptos metodológicos, ha- ciendo un comparativo entre los dos grupos territoriales en los que se tra- bajó.

La familia reconstituida está cimentada en creencias axiológicas de unión, tolerancia, paciencia, apoyo mutuo y amor para las dos familias participantes, siendo significado el amor en pareja por el participante de Ibagué como fundamental para el mantenimiento de la unión familiar. Del mismo modo, la reconstitución familiar se significa como un proceso generativo según los participantes, dando cuenta que de esta manera se posibilitó una nueva forma de vida, contar con una figura materna y paterna independientemente de no ser vínculos biológicos. Dentro de los modos deorganización está la posición periférica de los padres biológicos en el ejercicio del rol parental con permanencia intermitente. Las dos familias narran conflictos con la familia extensa del hombre. Finalmente, existe diferencia en el manejo de la economía del hogar, siendo asumida en la familia de Ibagué por el cónyuge, y en la familia de Soacha por la pareja.

Con respecto a la reintegración a la vida civil, las dos familias lo significan como una oportunidad de construir un hogar, de asumir el rol de madre por parte de la participante de Soacha y de vivir en tranquilidad, libertad y 
reencontrarse con la familia extensa, por parte del participante de Ibagué. El acompañamiento que han recibido de parte de la Agencia Colombiana de Reintegración ACR es connotado positivamente, reconociéndolo como un apoyo y un recurso adaptativo en el momento de asumir una estilo de vida urbano que los reta frente al manejo del dinero, a nuevas costumbres y nuevos modos de vivir en legalidad, siendo un habitus de la ciudad. Aun así, para el participante de Ibagué el mensaje para los combatientes es sin lugar a duda una invitación a unirse a la vida civil, mientras que para la participante de Soacha, esta debe ser una decisión libre y autónoma que no debe ser influenciada por nadie, teniendo en cuenta que el primero estuvo en el grupo armado por motivos económicos y la segunda por principio ideológicos. No se reconocen procesos de co evolución en donde la institución también considere que se ha movilizado, siendo un ritual unidireccional hacia el participante. Aun así, con el proceso investigativo/interventivo, se crea en una reintegradora la intención de poder crear nuevas formas de intervención con las familias desde la dimensión de trabajo familiar, alejándose de su voz de experticia. Las reintegradoras son interlocutoras privilegiadas desde las creencias de las familias, lo que les da el permiso de posicionarse como autoridad. Sin embargo, por parte de la reintegradora de Ibagué se visibiliza la autonomía de los participantes que difiere en algunos momentos de la ritualización directiva de la reintegradora de Soacha.

La experiencia en el contexto del conflicto armado para la participante de Soacha se narra desde el rol de guerrera que desde su infancia le generó interés, por la influencia del contexto social y cultural. Las armas, como símbolo de poder la llevaron a vincularse voluntariamente al grupo armado, en donde considera haber vivido una experiencia generativa a pesar del trato fuerte que recibió después de su periodo de entrenamiento.

El participante de Ibagué no quiso involucrarse directamente en las filas de la guerrilla, sin embargo, esta experiencia se generó miedo en los últimos momentos por amenazas recibidas.

Finalmente, el trabajo en red se posibilitó por medio de una conversación 'por Skype entre las dos familias, la reintegradora de Soacha y las investi- 
Evolución del concepto de familia desde la perspectiva legal. Estudio de caso gadoras/interventoras después de consensuar que las conversaciones tienen mayor impacto que los videos pregrabados, estrategia previamente pensada.

El trabajo en redes familiares permitió construir un encuentro empático a partir de las experiencias compartidas. Emerge el mito de que sí existe amor, es posible solucionar cualquier conflicto, trasmitiendo apoyo de una familia a otra para continuar luchando por el hogar, mensaje que pudo haber cumplido una función homeostática en el sistema, teniendo en cuenta la pauta de complementariedad rígida existente en la familia que vive la crisis conyugal, dando cuenta que el trabajo interfamiliar tuvo un impacto positivo con respecto a la construcción de redes de apoyo, pero pudo haber contenido el proceso de movilización de la familia de Ibagué.

\section{Discusión}

La hipótesis inicialmente formulada se estructuraba desde la relación pro- blemática de la reconstitución familiar y la reintegración con los procesos vinculares de las familias participantes. Sin embargo, la experiencia inves- tigativa/interventiva develó lo contrario, dando cuenta que para estas fa- milias, la dinámica subyacente a la reconstitución familiar y a la reintegra- ción a la vida civil han sido formas de auto-organización más que de irre- gularidad, entendiendo la auto-organización como el proceso de orden emergente al límite del caos (Kauffman, 1990, citado por Pérez, 2005 hace un tiempo atrás los lazos de consanguinidad.

La configuración de la dinámica de pareja, en la familia del GT1 especialmente, estuvo permeado por el contexto del conflicto y la reintegración. La conyugalidad con una persona civil para una ex-combatiente se connota inicialmente como una decisión difícil, por la diferencia de contextos de los que emergen los dos cónyuges, significando las relaciones de pareja como la unión de dos personas del mismo contexto o contextos similares. Con la creación de un vínculo conyugal entre un civil y una excombatiente, se interconectan patrones de organización y sistemas de significación que fluctúan hacia atractores diferentes (Maldonado y Gómez, 2011), entretejiendo un proceso auto-organizativo en el cual, la mujer transforma su pauta de imposición que la sitúa desde una pauta simétrica, 
sin posibilidad de "ceder", mientras que el hombre, desde su historia de vida, asume funciones parentales a temprana edad, co-construyendo nuevos significados alrededor de ser pareja y ser padres, incorporando la afectividad como fundamentales en la vinculación con los otros miembros de la familia.

Con respecto a la reintegración a la vida civil, esta fue una clara opción de auto-organización para los participantes ex - guerrilleros, quienes reconocieron desde el rol que desempeñaban en el grupo armado, militante o miliciano, la necesidad de propiciar un cambio en sus vidas. La transición de fase que se vive con la desmovilización y reintegración, ya supone un proceso evolutivo, que desde las ciencias de la complejidad, no es sinónimo de progreso sino de creación de nuevas posibilidades en la línea de tiempo de la vida, dado que como explican Bascompte y Luque (2012), "la noción de progreso deriva más de las expectativas socioculturales, que de una constatación objetiva del fenómeno evolutivo" (p.44). Dicha transición, que daba la posibilidad de que su derecho a la vida fuera vulnerado por retaliación interna, se vio motivada en la participante militante- del GT1, en acuerdo con Berrio y Cañón (2007) y Mejía (2014), por el nacimiento de sus hijas, que más allá del interés porque estas no repitan su historia, como lo menciona Mejía (2014), se da por la coacción de los roles de género, que son revolucionados por las necesidades biológicas de reproducción y la aparición de un evento histórico como lo es la maternidad, que transforma la prospectiva vital fundamentada en los mitos de la guerra, bifurcando su caminos, configurando nuevos sentidos de vida y dirigiéndolos hacia la elegibilidad de una vida civil, como escenario en el que es posible ofrecer un hogar para sus hijas y ser una madre para ellas. De allí que desde el rol de militante, se pueda convertir en predictor de procesos de reconstitución familiar, que desde el rol femenino, dicho proceso puede darse en los primeros años de vida de los hijos.

En el caso del participante miliciano o informante -GT2, la vinculación al grupo armado no imposibilitó trabajar en sus proyectos personales, los que en este caso, se articulaban de manera significativa con el mito de la unión familiar perdurable, dando así la posibilidad de establecer relaciones parentales generativas con los hijos de su pareja, guardando en secreto su condición de guerrillero. El miedo como motivador de la desvinculación 
del grupo armado, dado el riesgo inminente que corría a partir de su ejercicio de recolector y remisor de información y los rumores acerca de su no lealtad al grupo, no se menciona en las investigaciones consultadas, haciéndose presente en cambio en las razones por las que las personas continúan en el grupo armado (Mejía, 2014). El desplazamiento forzoso a partir de la desmovilización, que es obligatorio por posibles represarías del grupo delictivos de la zona sumado a la desconfianza de la comunidad y las acciones que las mismas puedan tomar, como lo explica la política del Consejo Nacional de Política Económica y Social (CONPES, 2008), fue generativo y movilizante para esta familia, significando la vida urbana como una prospectiva de vida esperada, cambio que demandó la adquisición de hábitus propios de la ciudad, a los que esta familia logró adaptarse con facilidad (distancia entre la casa y algunos servicios, el manejo del dinero), viendo esta transición como una oportunidad que de aprovechar las ventajas de la ciudad.

La familia configura el escenario de reintegración en donde germina el sentido de vida para estos participantes, al lado de la noción de libertad que es convocada paradójicamente por el participante miliciano, cuya participación voluntaria en el grupo armado no fue en condición de reclusión, comprendiendo que desde el rol de militante, cuya participación también se describe como voluntaria, entendiendo que dicha decisión fue tomada a los 12 años, la vinculación al conflicto emerge desde las ideologías quien encarna la guerrilla como institución social y política, siendo desde el rol de miliciano una alternativa laboral que no configura identidad. Del mismo modo, Berrio y Cañón (2007) precisan que, la familia posibilita los procesos de socialización de los individuos en lo psicosocial y cultural, favoreciendo la identidad y pertenencia a su núcleo familiar y a su entorno. En relación con lo mencionado y en acuerdo con las premisas de Camargo (2015), el fortalecimiento de los procesos vinculares en los sistemas familiares de los integrantes de la ARN es un elemento que puede asociarse directamente con prevención de la reincidencia, lo que demanda a la institución nuevas propuestas interventivas.

Por otro lado, desde la concepción de la excombatiente, la civilidad que asumen ellos como ex - guerrilleros no es la misma que para personas que siempre han vivido este como su contexto de socialización, dado que las 
cuentas que deben rendir posterior a la desmovilización representa un ritual distintivo en la posición que ocupan en la sociedad, dando cuenta de lo que Berrio y Cañón (2007) llaman desarraigo, como una sensación de ajenidad y de no pertenencia a la nueva ciudad, pero además, de la dificultad evidente que visibilizan los exguerrilleros frente a los prejuicios sociales que deben enfrentar al incorporarse a la sociedad con la que en algún momento se crearon relaciones de rivalidad.

\section{Conclusiones}

El contexto histórico permite entender que los modelos de conformación de familias cambian constantemente por las relaciones sociales que son considerablemente relevantes para el cambio del concepto de familia. Pero también puede deberse a factores culturales como por ejemplo el que se dio por muchos años en Colombia y países con fuertes costumbres reli- giosas, en el que éstas se plasman como normas jurídicas y son limitantes en el reconocimiento de las diferentes maneras en que los seres humanos conformaban una familia. Piénsese en el caso de países de tendencia cató- lica y los países árabes, en donde la ley civil no se diferencia muchas veces de las normas religiosas.

Se ha logrado analizar que la Carta Política es clara al definir el papel trascendental de la familia en el conglomerado social y que la interpretación constitucional del artículo 42, comprende que ésta se forma por la voluntad de conformarla, bien sea por vínculos jurídicos o naturales. Por tanto, esta interpretación incluyente y que reconoce la realidad social contemporánea, no restringe el derecho que les asiste a las personas para la conformación de familias en las que se incluyen las formadas por parejas del mismo sexo. Esto permite en consideración de los fallos de la Corte Constitucional, identificar que a pesar de una redacción más bien cerrada del artículo 42 de la Carta, si se ha dado jurisprudencialmente una amplitud para reconocer derechos a parejas del mismo sexo, dentro de un nuevo contexto histórico y antropológico. Queda pendiente el reconocimiento y aceptación cultural de esta realidad jurídica. 
Debido a que el comportamiento del hombre es regulado por normas que esperan del individuo un tipo de conductas, el concepto de familia está ligado a su misma evolución. Es pertinente anotar que la antropología permite identificar como las manifestaciones sociales y culturales de las comunidades estas están ligadas directamente al concepto de familia haciendo cambiar la forma en que este es entendido por la legislación. Esta revaloración de los conceptos y de lo permitido, genera tensiones que si bien, son más escenario de lo social y cultural, tengan como foro de discusión escenarios jurídicos como lo es la Corte Constitucional, acerca de lo que es permitido, siendo el balance actual, la protección en condiciones casi homólogas, pero con un duro trecho por recorrer.

Con relación al concepto de familia retomando a Kottak, las normas jurídicas tienen su génesis en el comportamiento de los seres humanos y a través de ellas se regulan instituciones como la familia. El concepto de antropología cultural adquiere relevancia para nuestro tema de estudio ya que permite entender de manera axiológica como el comportamiento humano y su entorno incide en la evolución del concepto de familia.

El derecho a la igualdad y la garantía del mismo es un requisito indispensable para que Colombia se convierta en un Estado estable como bien afirma Aristóteles "El único Estado estable es aquel en que todos los ciudadanos son iguales ante la ley” (Damm, 2008).

Finalmente, si bien estas familias dan cuenta del proceso de reintegración desde su experiencia generativa en él, frente a si la desmovilización es o no la salida (Ávila, 2013), la decisión de desmovilizarse para la participante es una elección totalmente autónoma, dado que considera su calidad de civil no equiparable con civilidad de las demás personas que no tuvieron relación con el conflicto, cargando la etiqueta de "ex - guerrilleros" por el resto de sus vidas, siendo entonces la reintegración un adyacente posible que sigue a continuación del conflicto, cuya única promesa es, como menciona Kauffman (2000, citado por Johnson, 2011), la expansión de lo posible, la ampliación de la diversidad de la vida, que puede o no ser la salida, puesto que para ello es necesario connotar el conflicto como una experiencia no deseada, visibilizar en la vida civil un mejor futuro posible pero 
Evaristo J. Miranda. Cindy K. Torres A. J.F. Agredo Morales

adicionalmente y encontrar, en corresponsabilidad con el Estado que los invita a esto, los caminos para organizarse en este nuevo escenario.

\section{Referencias}

Agencia Colombiana de Reintegración (s.f.a). Funciones y deberes. Tomado de http://www.reintegracion.gov.co/es

Agencia Colombiana de Reintegración (s.f.b). Reseña Histórica- Reintegración.

Tomado de http://www.reintegracion.gov.co/es

Agencia Colombiana de Reintegración (s.f.c). La reintegración en cifras. Tomado de http://www.reintegracion.gov.co/es

Agencia Colombiana de Reintegración (s.f.d). Corresponsabilidad. Tomado de http://www.reintegracion.gov.co/es/agencia/Paginas/corresponsabilidad.aspx

Agencia Colombiana para la Reintegración, (s.f. e). Evolución del Proceso de la Reintegración. Tomado de: http://www.reintegracion.gov.co/es/la-reintegracion/centro-de-documentacion/Documentos/ Evoluci $\% \mathrm{C} 3 \% \mathrm{~B} 3 \mathrm{n} \% 20 \mathrm{del} \% 20$ Proceso $\% 20 \mathrm{de} \% 20$ Reintegraci $\% \mathrm{C} 3 \% \mathrm{~B} 3 \mathrm{n} \% 20$ Fortaleza $\% 20$ Institucional $\% 20$ basada $\% 20$ en $\% 201 \mathrm{a} \% 20$ experiencia $\% 20 \mathrm{y} \% 20$ lecciones $\% 20$ aprendidas.pdf.

Amunátegui Perelló, Carlos Felipe. (2006). El origen de los poderes del "Paterfamilias" I: El "Paterfamilias" y la "Patria potestas". Revista de estudios histórico-jurídicos, (28), 37-143. Recuperado el 2 de diciembre 2016 de: http://www.scielo.cl/scielo.php?script=sci_arttext\&pid=S071654552006000100002

Andrade, G. (2009). I memoriam: Claude Levi-Strauss. Revista Venezolana de Información, Tecnología y Conocimiento. (3), 111 - 113. Recuperado el 22 de 05 de 2016 de: www.redalyc.org/pdf/823/82311846009.pdf

Arranz, E., Oliva, A., Olabarrieta, F., \& Antolín, L. (2010). Análisis comparativo de las nuevas. Infancia y Aprendizaje, 503 - 513. Recuperado el 20 de 08 de 2016, de https://www.u-cursos.cl/facso/2011/2/PSI-PD2/2/material_docente/bajar?id_material $=586840$.

Ávila, J. H. (2013). Calidad de vida en ex integrantes de un grupo armado ilegal reubicados en una capital urbana. Realitas. Revista de Ciencias Sociales, Humanas y Artes, 1(1), 19-24. 
Baptiste, D. (1983). Family Therapy with reconstituted families: A crisis- induction approach. American Journal of Family Therapy, 11.

Berrio, D. y Cañón, S. (2007). El rol que desempeña la familia de la población en situación de desmovilización en su proceso de inclusión al programa de atención humanitaria (PAHD) en un hogar de paz de exguerrilleros del ministerio de defensa durante el segundo semestre de 2006 (Trabado de grado Pregrado). Bogotá D.C.: Universidad de la Salle. Tomado de http:// repository.lasalle.edu.co/bitstream/handle/10185/13277/T62.07\%20B459r.pdf?sequence $=1$ \&isAllowed $=\mathrm{y}$

Bustos, M. L. (2003). Génesis 2: El hombre en el huerto del edén. Recuperado el 11 de 09 de 2016, de http://www.sindioses.org/genesis/genesis2.html

Calvo, M. J. y Capozzi, R. (1999). Relaciones literarias entre Jorge Luis Borges y Umberto Eco. España: Universidad de Castilla - La Mancha.

Camargo, E. (2015). Familia, trabajo y sociedad en el proceso de reintegración de mujeres desmovilizadas. Encuentro latinoamericano, 2 (2), 53-77.

Carmona, E. A. (04 de Mayo de 2010). Principios del Tratado Internacional. Obtenido de Derecho Internacional: http://derechointernacional02.blogspot.com.co/2010/05/principios-del-tratado-internacional.html

Constitución Política de Colombia. (1991). Constitución Nacional de Colombia. Recuperado el 10 de 01 de 2016, de http://www.alcaldiabogota.gov.co/sisjur/normas/Norma1.jsp?i $=4125$

Consejo Nacional de Política Económica y Social, (2008). Política de Reintegración social y económica de personas y grupos alzados en armas. Tomado de http://www.reintegracion.gov.co/es/la-reintegracion/centro-de-documentacion/Documentos/Documento $\% 20$ Conpes $\% 203554 \%$

$201 \% 20 \mathrm{Pol} \%$ C3\%ADtica $\% 20$ nacional $\% 20 \mathrm{de} \% 20$ reintegraci $\%$ C $3 \%$ B 3 n $\% 20$ social $\% 20 y \% 20$ econ $\%$ C $3 \%$ B3mica $\% 20$ para $\% 20$ personas $\% 20 y \% 20$ grupos $\% 20$ armados $\% 20$ ilegales.pdf

Coral y Torres, M. C. (2002). Instituciones de Derecho de Familia. Bogotá: Ediciones Doctrina y Ley Ltda.

Corte Constitucional (1996). Sentencia C-098 del 7 de marzo de 1996. Obtenido de: http://www.corteconstitucional.gov.co/relatoria/1996/c-098-96.htm

Corte Constitucional (2007). Sentencia C-075 del 7 de febrero de 2007: Obtenido de: http://www.corteconstitucional.gov.co/relatoria/2007/c-075-07.htm Última recuperación: 5 de diciembre de 2016 
Corte Constitucional (2007). Sentencia C-811 del 3 de octubre de 2007. Obtenido de: http://www.corteconstitucional.gov.co/relatoria/2007/c-811-07.htm Última recuperación: 5 de diciembre de 2016

Corte Constitucional (2008). Sentencia C-336 del 9 d mayo de 2007: Obtenido de: http://www.corteconstitucional.gov.co/RELATORIA/2007/C-33607.htm Última recuperación: 5 de diciembre de 2016

Corte Constitucional (2008). Sentencia C-798 del 20 de agosto de 2008. Obtenido de: http://www.corteconstitucional.gov.co/relatoria/2008/c-798-08.htm Última recuperación: 5 de diciembre de 2016

Corte Constitucional (2009). Sentencia C-029 del 28 de enero de 2009. Obtenido de: http://www.corteconstitucional.gov.co/relatoria/2009/c-029-09.htm Última recuperación: 5 de diciembre de 2016

Corte Constitucional (2009). Sentencia T-572 del 26 de agosto de 2009. Obtenido de http://www.corteconstitucional.gov.co/relatoria/2009/t-572-09.htm Última recuperación: 5 de diciembre de 2016

Corte Constitucional (2010). Sentencia T-051 del 2 de febrero de 2010. Obtenido de: http://www.corteconstitucional.gov.co/relatoria/2010/t-051-10.htm Última recuperación: 5 de diciembre de 2016

Corte Constitucional (2011). Sentencia C-577 del 26 de julio de 2011. Obtenido de: http://www.corteconstitucional.gov.co/relatoria/2011/c-577-11.htm Última recuperación: 5 de diciembre de 2016

Corte Constitucional (2013). Sentencia T-606 del 2 de Septiembre de 2013. Obtenido de: http://www.corteconstitucional.gov.co/relatoria/2013/t-60613.htm Última recuperación: 5 de diciembre de 2016

Corte Constitucional (2016). Sentencia SU-214 del 28 de abril de 2016. Obtenido de: http://www.corteconstitucional.gov.co/relatoria/2016/su214-16.htm Última recuperación: 5 de diciembre de 2016

Damm, A. (2008). Asuntos Capitales de Aristóteles. Recuperado el 10 de 05 de 2016, de http:/ / www.asuntoscapitales.com/puntoi.asp?idp=55

Díaz de Guijarro, E. D. (02 de 2016). Fragmento del Tratado de derecho de Familia. Obtenido de www.juridicas.unam.mx: http://www.juridicas.unam.mx/publica/librev/rev/indercom/cont/24/bib/bib25.pdf. Última recuperación: 5 de diciembre de 2016

Enciclopedia Jurídica, e. (2014). Enciclopedia jurídica. Obtenido de http://www.enciclopedia-juridica.biz14.com/d/ley-especial/ley-especial.htm Última recuperación: 5 de diciembre de 2016 
Engels, F. (1884). El Origen de La Familia La propiedad Privada Y el Estado. Moscú: Editorial Progreso.

Enrique Arranz, A. O. (2010). Análisis comparativo de las nuevas estructuras familiares como contextos potenciadores del desarrollo Psicológico Infantil. Universidad del País Vasco, Universidad de Sevilla.

Estrada-Vélez, S. (2011). Familia, Matrimonio y Adopción: Algunas Reflexiones en defensa del derecho de las parejas del mismo sexo a constituir Familia y de los menores a tenerla. Revista de Derecho.

Estupiñán, J., Hernández, A. y Bravo, L. (2006a). Vínculos, ecología y redes. Dossier No. 1. Bogotá D.C.: Universidad Santo Tomás.

Estupiñán, J., Garzón, D., Niño, J. A. y Rodríguez, L. (2006b). Consultoría sistémica. Un enfoque interventivo, formativo e investigativo. Bogotá D.C.: Universidad Santo Tomás.

Focault, M. (1997). La historia de la sexualidad. México D.F., Siglo Veintiuno Editores.

Hernández y Ortega, C. A. (2013). Derecho de Familia, 18 tendencias Contemporáneas del derecho. Bogotá: Editores Académicos.

Johnson, S. (2011). Las buenas ideas: Una historia natural de la innovación. España: Turner Publicaciones.

Kottak, C. (2003). Espejo para la humanidad Introducción a la antropologíacultural. Madrid: McGrawHill.

Lorenzo-Rego I, I. L. (2014). El Concepto de Familia en el Derecho Español: Un estudio Interdisciplinar. J.M. BOSCH.

Maldonado, C. y Gómez, N. (2011). El Mundo de las Ciencias de la Complejidad. Tomado de http://www.ugr.es/ raipad/investigacion/excelencia/seminarioXV/2011_el_mundo_de_las_ciencias_de_la_complejidad.pdf

Mejía, L. (2014). La reintegración social y económica de los grupos armados ilegales en Colombia: Reflexiones a partir de la trayectoria de nueve excombatientes (Trabajo de grado de Maestría). Bogotá D.C.: Universidad Colegio Mayor de Nuestra Señora del Rosario.

Monroy, M. (2012). Derecho de Familia, Infancia y Adolescencia. Bogotá: Librería Ediciones del Profesional LTDA.

Oliva, E., y Villa, V. J. (2014). Hacia un concepto interdisciplinario de la familia en la globalización. Justicia Juris, Universidad Autónoma del Caribe, 11-20. 
Pakman, M. (1999). Investigación e intervención en grupos familiares. Una perspectiva constructivista. En Delgado y Gutiérrez, Métodos y Técnicas Cualitativas de Investigación en Ciencias Sociales. Madrid: Editorial Síntesis.

Peña-Huertas R. y Hurtado M. (2014) Tensión entre la democracia inclusiva y la mayoría: el matrimonio igualitario en el Congreso Colombiano. Revista de derecho, Universidad del Norte, 42: 1-95.

Pérez, A. (2005). La obra de Stuart Kauffman. Aportaciones a la biología del siglo XXI e implicaciones filosóficas. Tomado de http://eprints.ucm.es/5521/1/la_obra_de_stuart_kauffman.__ apor taciones_a_la_biolog $\%$ c3\% $\%$ da_del_siglo_xxi_e_implicaciones_filos $\%$ C3\% $\% 3$ FICAS.pdf

Rodríguez y Serrano, R. R. (2005). El concepto de Matriarcado: Una revisión crítica. Revista sobre Arqueología en Internet.

Talciani, H. C. (1990). Concepto y Reconocimiento Legal de la Familia de Hecho. Revista Chilena de Derecho, 35 - 85. Recuperado el 3 de 11 de 2016, de https://dialnet.unirioja.es/descarga/articulo/2649674.pdf 